\title{
Trends in emergency department use by older people during the COVID-19 pandemic
}

\author{
Fergal Howley ${ }^{1,2} \cdot$ Amanda Lavan $^{1,2,3} \cdot$ Eimear Connolly ${ }^{1,3} \cdot$ Geraldine McMahon $^{2,3} \cdot$ Mustafa Mehmood $^{2,3}$. \\ Robert Briggs ${ }^{1,2,3}$
}

Received: 20 May 2021 / Accepted: 1 July 2021 / Published online: 17 July 2021

(c) The Author(s) 2021

\section{Key Summary Points}

Aim To examine changing trends in presentation of older people to the emergency department during the COVID-19 pandemic compared to 2018/2019.

Findings On average 4 fewer people aged $\geq 70$ years presented to the ED in the first 6 months of the COVID-19 pandemic (March-August 2020). There was a 20\% reduction in presentations of stroke and cardiac complaints but a 25\% increase in falls/injuries following easing of lockdown restrictions.

Message It is imperative that we consider enabling strategies to ensure older people access unscheduled care in a timely manner when necessary.

\begin{abstract}
Purpose Reports suggest that many older people deferred seeking healthcare during the COVID-19 pandemic due to fear of contracting COVID-19. The aim of this study was to examine trends of emergency department (ED) use by older people during the first wave of the COVID-19 pandemic compared to previous years.

Methods The study site is a 1000-bed university teaching hospital with annual ED new-patient attendance of $>50,000$. All ED presentations of patients aged $\geq 70$ years from March to August 2020, 2019 and 2018 inclusive $(n=13,989)$ were reviewed and compared for presenting complaint, Manchester Triage Score, and admission/discharge decision.

Results There was a 16\% reduction in presentations across the 6 months in 2020 compared to the average of 2018/2019. On average, 4 fewer people aged $\geq 70$ years presented to the ED per day in 2020. Much of this was concentrated in March (33\% fewer presentations) and April (31\% fewer presentations), when the country was in 'lockdown', i.e. non-essential journeys were banned. There was a $20 \%$ reduction in patients presenting with stroke and cardiac complaints. In the 3 months following easing of restrictions, there was a $25 \%$ increase in falls and orthopaedic injuries when compared to 2018/2019.

Conclusion This study demonstrates a significant decline in the number of older people presenting to the ED for unscheduled care, including for potentially time-dependent illnesses such as stroke or cardiac complaints. Given the possibility of further lockdowns, it is imperative that we consider enabling strategies to ensure older people access unscheduled care in a timely manner when necessary.
\end{abstract}

Keywords COVID-19 $\cdot$ Emergency Department $\cdot$ Falls $\cdot$ Delirium

Robert Briggs

briggsr@tcd.ie

1 Mercer's Institute for Successful Ageing, St James's Hospital, James's St, Dublin 8, Ireland

2 Department of Emergency Medicine, St James's Hospital, James's St, Dublin 8, Ireland

3 Discipline of Medical Gerontology, Trinity College Dublin, Dublin 1, Ireland

\section{Background}

The emergency department (ED) is the commonest pathway by which older people access acute hospital care when unwell [1]. Currently, 20\% of patients presenting to the ED are aged $\geq 65$ years [2] while the number of older people presenting to EDs for unscheduled care has increased steadily in recent years against a backdrop of increased longevity generally and enhanced survival with multimorbidity and 
frailty [3]. Furthermore, it is projected that there will be a further marked acceleration in ED presentations in those aged $\geq 85$ years in coming years [4].

Older people with COVID-19 are more likely to become unwell, to require hospitalisation and to die from the illness $[5,6]$. From the early stages of the COVID- 19 pandemic in Ireland, older people, as well as younger people with underlying medical illnesses, were advised to 'cocoon', i.e. stay indoors, and avoid face-to-face contact with other people to prevent transmission of COVID-19 within this vulnerable cohort, and to reduce pressure on emergency medical services [7]. Initial advice was to leave the house for essential reasons only. Similar strategies were applied elsewhere, with alternative terminology used such as shielding or protective isolation [8].

Following the announcement of these emergency measures, reports highlighted a significant reduction in the rate of ED presentations including in both the UK and the US [9, 10]. At the same time, a worrying pattern emerged among medical specialties of a reduction in acute presentations with complaints such as abdominal pain, chest pain or stroke, raising concerns that patients, particularly older patients most at risk from COVID-19, were delaying or avoiding seeking healthcare when unwell $[11,12]$. In Ireland, the Chief Medical Officer issued a statement on 2nd April 2020 to remind the public that hospitals were open 'for all ailments, not just COVID-19' [13]. These concerns were supported by data suggesting 1-in-6 frail, older adults deferred seeking healthcare during the early months of the first wave [14]. As yet, no study has examined the impact of the COVID-19 pandemic on ED presentation specifically in an older cohort.

The aim of this study, therefore, was to examine the trends of ED utilisation by older people in a large urban teaching hospital during initial months of the first wave of the COVID-19 pandemic compared to similar periods in previous years. In addition, we wished to determine the impact of the COVID-19 pandemic on frailty-related presentations such as falls, delirium and stroke. Our hypothesis was, while overall numbers of presentations would be lower, that weekly and monthly trends would be influenced by, and run parallel with, public-health restrictions in place at the time, particularly those pertaining to older people and cocooning.

\section{Methods}

This study delineates the number and nature of ED presentations in people aged $\geq 70$ years during the first wave of the COVID-19 pandemic, compared to the same timepoints in 2018 and 2019, in a large urban university teaching hospital.

\section{Study design}

The study site is a 1,000-bed university teaching hospital with an ED attendance of over 50,000 presentations per annum. St James's Hospital has a stroke unit, and is a hub centre for cardiology, oncology, and haematology. It ran COVID-19-specific wards during the pandemic but also continued to care for non-COVID-19 illness.

All patient presentations to the ED from March to August 2020, 2019 and 2018 inclusive were reviewed retrospectively and the following information was collated for each presentation:

- Number of presentations each month

- Demographic details including age and sex

- Manchester Triage Score

- Presenting complaint based on triage note

- Admission decision

Presenting complaint was further distilled into the following categories:

- Respiratory: breathlessness, cough, haemoptysis, or pleuritic pain

- Cardiac: chest pain, arrhythmia, palpitations

- Stroke

- Delirium

- Orthopaedic/bony injury

- Non-orthopaedic injury

- Falls: fall, faint, dizziness

- Gastrointestinal: abdominal pain, vomiting, diarrhoea, constipation, gastrointestinal bleeding

- Non-stroke neurological: seizure, headache

- Gynae/urological: flank pain, groin pain, dysuria, haematuria, urinary retention, lower abdominal pain, vaginal bleeding

- Mental health

- Eye/ear/nose/throat

- Other

Clinical categorisation of presenting complaints was based on the Hospital Inpatient Enquiry (HIPE) Code selected at triage by nursing staff when the patient presented to the ED. HIPE is the principal source of national data on discharges from acute hospitals in Ireland. Some categories we used included more than one HIPE code, for example, falls was used to code for patients with fall, faint, or dizziness HIPE code. Orthopaedic injuries were considered separately, even though the mechanism of injury could be fall-related, as their HIPE code focussed only on the injury, e.g. wrist pain. Similarly, the 'delirium' categorisation was based on selection of delirium or confusion HIPE code at triage, rather than on an objective assessment performed in the ED. 
Each of the 6 months of interest were divided into 3 periods of at least 10 days each (with the final period of interest for each month lasting 10-11 days) to facilitate comparisons between different years. For example, March was divided into 3 separate periods from 1st to 10th, from 11 to 20th and from 21 to 31 st and so on.

\section{Ethics}

Ethical approval for this service analysis was obtained from the St James's Hospital Research \& Innovation Office (Project No 6300).

\section{Statistical analysis}

Data were analysed using Stata version 14.1 (Stata $\AA$, College Station, TX). Data were presented descriptively. Proportions were presented with $95 \%$ confidence intervals.

A logistic regression model with admission to hospital as the dependant variable was used to assess the association with presentation during the COVID-19 pandemic. Covariates were chosen a prior based on their likelihood of association with admission to hospital and included age, sex, MTS and presenting complaint.

A $p$ value $\leq 0.05$ was considered statistically significant.

\section{Results}

\section{Total presentations}

The baseline characteristics of the study sample are outlined in Table 1 . The mean age was 80 years and $54 \%$ were female.
The trends in presentation numbers, alongside government advice regarding current COVID-19 restrictions at specific timepoints, are shown in Fig. 1 and Table 2.

On average there were 4,922 presentations of patients aged $\geq 70$ years to the ED from March to August inclusive in 2018 and 2019, compared to 4,146 for the same period in 2020 , representing a $16 \%$ overall reduction in acute presentations across the 6 months. The relative proportion of ED visits from patients aged $\geq 70$ years did not change significantly, however, from $19.9 \%$ in $2018 / 2019$ to $20.0 \%$ in 2020 .

Much of this reduction in numbers presenting to the ED was concentrated in late March and April, when the country was in 'lockdown', i.e. non-essential journeys were banned. In March 2020, there were 531 presentations of people aged $\geq 70$ years, an average of 17 per day, compared to an average of 797 across March 2018 and 2019 or 26 per day, a one-third reduction in the number of presentations. There was a similar reduction of $31 \%$ in the number of presentations of older people to the ED in April 2020.

On May 5th, 2020, lockdown restrictions were eased, and the public were advised that they could travel up to $5 \mathrm{~km}$ from their home and those who were cocooning were advised they could leave their homes for exercise. There was a $15 \%$ reduction in ED presentations in May 2020 when compared to the 2018 and 2019 figures. There was a $2 \%$ increase in the number of presentations in June 2020 compared to the average form June 2018 and 2019 and the same number of patients presented in July 2020 when compared to the average from 2018 and 2019.

After an initial opening of services such as hairdressers and gyms in late June 2020, further easing of restrictions was deferred in August due to rising case numbers. In August 2020, there was a $16 \%$ decrease in presentations from 878 in 2018/2019 (28 per day) to 740 in 2020 ( 24 per day).
Table 1 Baseline characteristics of study sample by year of presentation

\begin{tabular}{lll}
\hline & March-Aug 2020 & March-Aug 2018/2019 \\
\hline Number of presentations (n) & 4,146 & 4,922 (average) \\
Age (years), mean (95\% CI) & $79.8(79.6-80.0)$ & $80.1(80.0-80.2)$ \\
Age breakdown & $0.56(0.54-0.57)$ & $0.55(0.54-0.56)$ \\
70-79 years & $0.37(0.36-0.39)$ & $0.37(0.36-0.38)$ \\
80-89 years & $0.07(0.06-0.08)$ & $0.08(0.08-0.09)$ \\
$\geq 90$ years & & \\
Female sex (prop. with 95\% CI) & $0.54(0.52-0.55)$ & $0.54(0.53-0.55)$ \\
MTS, mean (95\% CI) & $2.75(2.73-2.77)$ & $2.70(2.69-2.72)$ \\
MTS categories (prop. with 95\% CI) & $0.02(0.01-0.02)$ & $0.02(0.02-0.02)$ \\
Cat 1 & $0.34(0.33-0.36)$ & $0.39(0.38-0.40)$ \\
Cat 2 & $0.52(0.51-0.54)$ & $0.47(0.46-0.48)$ \\
Cat 3 & $0.11(0.10-0.12)$ & $0.12(0.11-0.12)$ \\
Cat 4 & $0.00(0.00-0.01)$ & $0.01(0.01-0.01)$ \\
Cat 5 & & \\
Admitted to hospital (prop. with 95\% CI) & $0.57(0.56-0.59)$ & $0.55(0.54-0.56)$ \\
\hline
\end{tabular}

$\mathrm{n}=$ number; $\mathrm{CI}=$ confidence interval; Prop. $=$ proportion; $\mathrm{MTS}=$ Manchester Triage Score Cat $=$ Category 


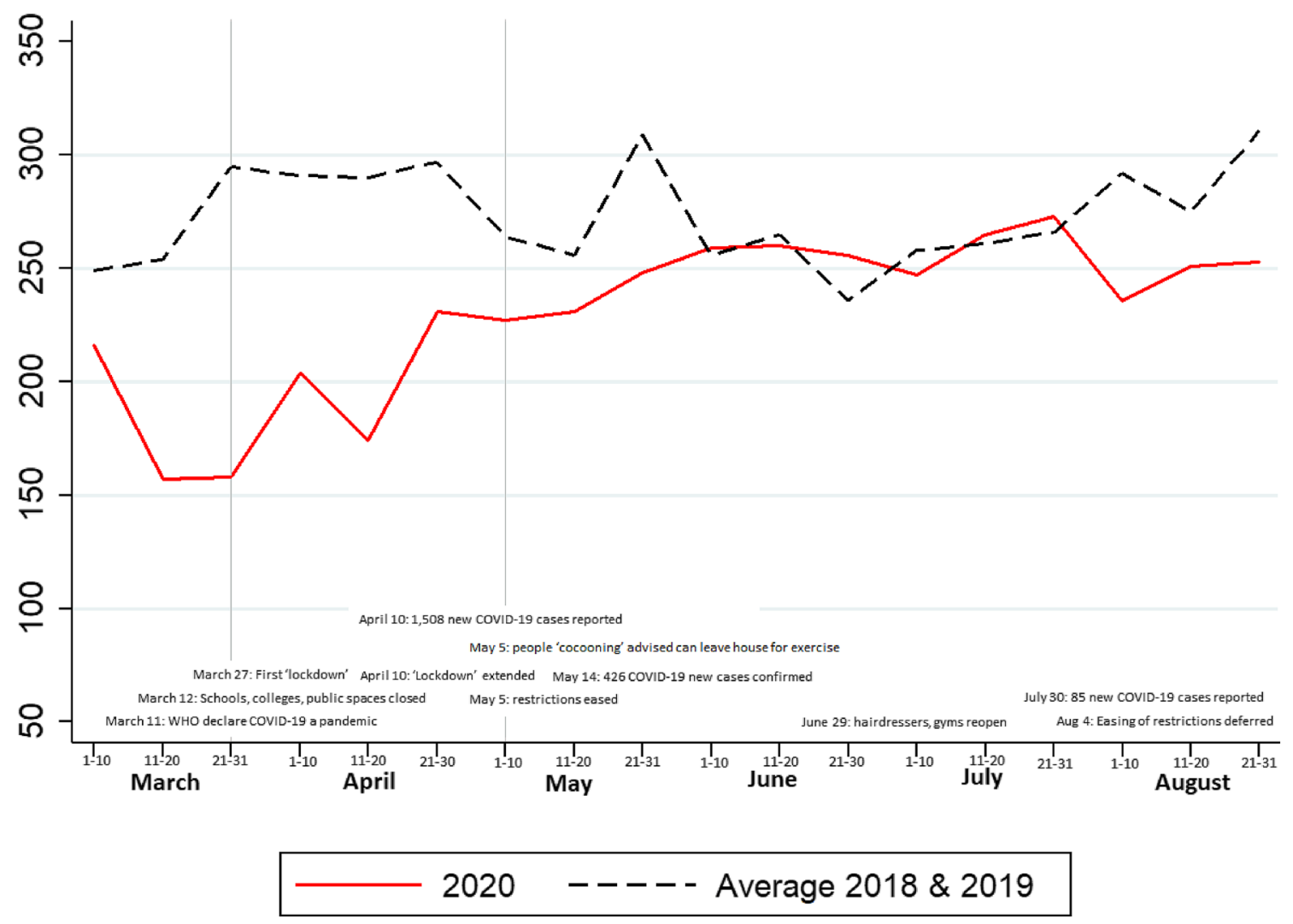

Fig. 1 Number of presentations of patients aged $\geq 70$ years to the emergency department during Wave 1 of the COVID-19 pandemic compared to 2018/2019. Data presented are absolute numbers of patients aged $\geq 70$ years presenting to the emergency department dur-

\section{Presentations by illness type}

Figure 2 and Table 2 further demonstrate the change in presentation trends for specific illnesses of interest, comparing March-August 2020 to 2018 and 2019.

Presentations with respiratory illness dropped by $8 \%$ overall in 2020 compared to prior years. After a significant initial decline in case numbers in March 2020 (by over 40\%), there was a smaller difference (4\% drop) in numbers across the 5 subsequent months and the relative proportion of cases comprised of respiratory illnesses remained stable.

Presentations with cardiac problems were $20 \%$ less frequent during the initial 6 months of the COVID-19 pandemic compared to the same periods in 2018 and 2019. This equated to an average of 17 fewer older people per month presenting to the ED with a cardiac-related complaint. The relative proportion of patients presenting with cardiac problems remained stable, however, at 9.4\% (95\% CI 8.6-10.4) in 2020 compared to $10.0 \%$ (95\% CI 9.4-10.6) in 2018/2019.

There was also a $20 \%$ reduction in the numbers of older people presenting with stroke during the first 6 months of the COVID-19 pandemic, compared to 2018/2019, with a ing Wave 1 of the COVID-19 pandemic from March to August 2020, compared to the average number of presentations across the same months in 2018 and 2019

reduction of 22\%, 14\% and 39\% in March, April and May 2020 , respectively. While numbers presenting with stroke were higher in June 2020 with a $15 \%$ increase and there was no change in July 2020, there was a subsequent decline in August 2020 (15\% lower).

There was an almost 50\% reduction in presentations of delirium from March to May 2020 inclusive when compared to 2018/2019. In the 3 months (June-August 2020 inclusive) following the easing of cocooning restrictions, i.e. the advice that older people cocooning could go outside for exercise, there was a $25 \%$ increase in the numbers of older people presenting with delirium when compared to 2018/2019. Over $40 \%$ more older people presented with delirium from June to August 2020 than from March to April 2020.

Overall, there was a $14 \%$ increase in the number of older people presenting with falls from March to August 2020 compared to similar time periods in 2018/2019. Falls made up a significantly higher proportion of the ED cases in 2020 compared to prior years. While there a drop in presentations in April and May, there was a significant increase in numbers presenting with falls in June, July and August 2020. Similar trends were seen for orthopaedic injuries, with a decline in 
Table 2 Trends in presentation of older people to the emergency department during the COVID-19 pandemic by presentation type

\begin{tabular}{|c|c|c|c|c|c|c|c|}
\hline & Total & Resp. & Cardiac & Stroke & Delirium & Falls & Ortho \\
\hline March-August $2020(n)$ & 4,146 & 701 & 391 & 116 & 140 & 744 & 281 \\
\hline Average 2019/2018 (n) & 4,922 & 769 & 491 & 148 & 164 & 651 & 335 \\
\hline$\%$ Change in 2020 & $-16 \%$ & $-8 \%$ & $-20 \%$ & $-22 \%$ & $-14 \%$ & $+14 \%$ & $-16 \%$ \\
\hline Rel. prop. 2020 & - & $16.9(15.8-18.1)$ & $9.4(8.6-10.4)$ & $2.8(2.3-3.3)$ & $3.4(2.9-4.0)$ & $17.9(16.8-19.1)$ & $6.5(5.8-7.3)$ \\
\hline Rel. prop. 2019/2018 & - & $15.6(14.9-16.3)$ & $10.0(9.4-10.6)$ & $3.0(2.7-3.4)$ & $3.3(3.0-3.7)$ & $13.2(12.6-13.9)$ & $6.8(6.3-7.3)$ \\
\hline March $2020(n)$ & 531 & 104 & 51 & 18 & 15 & 116 & 36 \\
\hline Average $2019 / 2018(n)$ & 797 & 180 & 79 & 22 & 31 & 98 & 71 \\
\hline$\%$ Change & $-33 \%$ & $-42 \%$ & $-35 \%$ & $-14 \%$ & $-52 \%$ & $+18 \%$ & $-50 \%$ \\
\hline Rel. prop. 2020 & - & $19.6(16.4-23.2)$ & $9.6(7.4-12.4)$ & $3.4(2.1-5.3)$ & $2.8(1.7-4.6)$ & $21.8(18.5-25.6)$ & $6.8(4.9-9.3)$ \\
\hline Rel. prop. 2019/2018 & - & $18.2(16.4-20.2)$ & $9.9(8.5-11.5)$ & $2.8(2.1-3.7)$ & $3.8(3.0-4.9)$ & $12.2(10.7-13.9)$ & $8.9(7.6-10.4)$ \\
\hline April $2020(n)$ & 609 & 140 & 57 & 17 & 19 & 94 & 48 \\
\hline Average $2019 / 2018(n)$ & 877 & 151 & 103 & 28 & 33 & 101 & 56 \\
\hline$\%$ Change & $-31 \%$ & $-7 \%$ & $-45 \%$ & $-39 \%$ & $-42 \%$ & $-7 \%$ & $-14 \%$ \\
\hline Rel. prop. 2020 & - & $23.0(19.8-26.5)$ & $9.4(7.3-12.0)$ & $2.8(1.7-4.4)$ & $3.1(2.0-4.8)$ & $15.4(12.8-18.5)$ & $7.9(6.0-10.3)$ \\
\hline Rel. prop. 2019/2018 & - & $17.2(15.5-19.0)$ & $11.7(10.3-13.3)$ & $3.2(2.5-4.1)$ & $3.7(2.9-4.7)$ & $11.5(10.1-13.1)$ & $6.4(5.3-7.6)$ \\
\hline May $2020(n)$ & 706 & 125 & 78 & 20 & 18 & 126 & 44 \\
\hline Average $2019 / 2018(n)$ & 829 & 127 & 91 & 32 & 38 & 128 & 76 \\
\hline$\%$ Change & $-15 \%$ & $-2 \%$ & $-14 \%$ & $-38 \%$ & $-53 \%$ & $-2 \%$ & $-42 \%$ \\
\hline Rel. prop. 2020 & - & $17.7(15.1-20.7)$ & $11.0(8.9-13.6)$ & $2.8(1.8-4.4)$ & $2.5(1.6-4.0)$ & $17.8(15.2-20.9)$ & $6.2(4.7-8.3)$ \\
\hline Rel. prop. $2019 / 2018$ & - & $15.3(13.7-17.1)$ & $11.0(9.6-12.6)$ & $3.9(3.0-4.9)$ & $4.5(3.6-5.6)$ & $15.4(13.8-17.3)$ & $4.6(3.7-5.7)$ \\
\hline June $2020(n)$ & 775 & 110 & 82 & 22 & 22 & 125 & 55 \\
\hline Average $2019 / 2018(n)$ & 757 & 101 & 60 & 19 & 20 & 112 & 52 \\
\hline$\%$ Change & $+2 \%$ & $+9 \%$ & $+37 \%$ & $+15 \%$ & $+10 \%$ & $+12 \%$ & $+6 \%$ \\
\hline Rel. prop. 2020 & - & $14.2(11.9-16.8)$ & $10.6(8.6-13.0)$ & $2.8(1.9-4.3)$ & $2.8(1.9-4.3)$ & $16.1(13.7-18.9)$ & $7.1(5.5-9.1)$ \\
\hline Rel. prop. 2019/2018 & - & $13.3(11.7-15.1)$ & $7.9(6.6-9.3)$ & $2.5(1.8-3.4)$ & $2.6(1.9-3.5)$ & $14.8(13.1-16.7)$ & $6.9(5.7-8.3)$ \\
\hline July $2020(n)$ & 785 & 103 & 71 & 22 & 35 & 152 & 50 \\
\hline Average $2019 / 2018(n)$ & 785 & 123 & 79 & 22 & 23 & 113 & 29 \\
\hline$\%$ Change & $0 \%$ & $-16 \%$ & $-10 \%$ & $0 \%$ & $+52 \%$ & $+35 \%$ & $+72 \%$ \\
\hline Rel. prop. 2020 & - & $13.1(10.9-15.7)$ & $9.0(7.2-11.3)$ & $2.8(1.9-4.2)$ & $4.5(3.2-6.2)$ & $19.4(16.7-22.3)$ & $6.4(4.9-8.3)$ \\
\hline Rel. prop. 2019/2018 & - & $15.6(13.9-17.5)$ & $10.0(8.6-11.6)$ & $2.7(2.0-3.7)$ & $2.9(2.1-3.8)$ & $14.4(12.8-16.2)$ & $3.6(2.8-4.7)$ \\
\hline Aug $2020(n)$ & 740 & 119 & 52 & 17 & 31 & 131 & 52 \\
\hline Average $2019 / 2018(n)$ & 878 & 123 & 80 & 26 & 21 & 100 & 48 \\
\hline$\%$ Change & $-16 \%$ & $-3 \%$ & $-35 \%$ & $-35 \%$ & $+48 \%$ & $+31 \%$ & $+8 \%$ \\
\hline Rel. prop. 2020 & - & $16.1(13.6-18.9)$ & $7.0(5.4-9.1)$ & $2.3(1.4-3.7)$ & $4.2(3.0-5.9)$ & $17.7(15.1-20.6)$ & $6.5(4.9-8.5)$ \\
\hline Rel. prop. $2019 / 2018$ & - & $14.0(12.5-15.7)$ & $9.1(7.8-10.5)$ & $2.9(2.2-3.8)$ & $2.4(1.8-3.2)$ & $11.3(9.9-12.9)$ & $5.9(4.9-7.1)$ \\
\hline
\end{tabular}

Data presented are absolute numbers of patients aged $\geq 70$ years presenting to the emergency department by presenting complaint and month during Wave 1 of the COVID-19 pandemic, compared to average numbers in 2018/2019, as well as relative proportions of cases (with 95\% confidence interval) related to each presenting complaint

$\mathrm{n}=$ number; $\%=$ percentage; rel. prop. = relative proportion of cases

the early stages of the pandemic from March to May, followed by increased numbers when compared to 2018/2019 from June to August inclusive. In the 3 months following the easing of cocooning restrictions, there was a $25 \%$ increase (From an average of 454 in 2018/2019 to 565 in 2020) in falls and orthopaedic injuries involving older people presenting to the ED when compared to previous years.

\section{Presentation acuity and likelihood of admission}

Older patients presenting from March to August 2020 were more likely to be admitted to hospital than in 208/2019, with a $57 \%(2383 / 4146)$ admission rate compared to $55 \%$ (2726/4922 on average) across the same months in 2018 and $2019\left(\mathrm{X}^{2}=5.209 ; \mathrm{p}=0.022\right)$.
The mean MTS was higher in those presenting in 2020 (2.75 (95\% CI 2.73-2.77) vs 2.70 (95\% CI 2.69-2.72); $t=-3.297 ; p=0.001)$ suggesting lower severity illness despite this higher admission rate.

As shown in Table 3, presentation during the COVID19 pandemic was associated with an $18 \%$ higher likelihood of admission compared to 2018/2019 after adjusting for covariates of age, sex, MTS and presenting complaint. Other predictors of admission were male sex, age $\geq 80$ years and presentation with respiratory illness, stroke, or delirium. Presenting with an orthopaedic injury and MTS $>2$ was associated with lower likelihood of admission. 
Fig. 2 Number of presentations of patients aged $\geq 70$ years to the emergency department by presenting complaint during Wave 1 of the COVID-

19 pandemic compared to 2018/2019. Data presented are absolute numbers of patients aged $\geq 70$ years presenting to the emergency department during Wave 1 of the COVID19 pandemic from March to August 2020, compared to the average number of presentations across the same months in 2018 and 2019
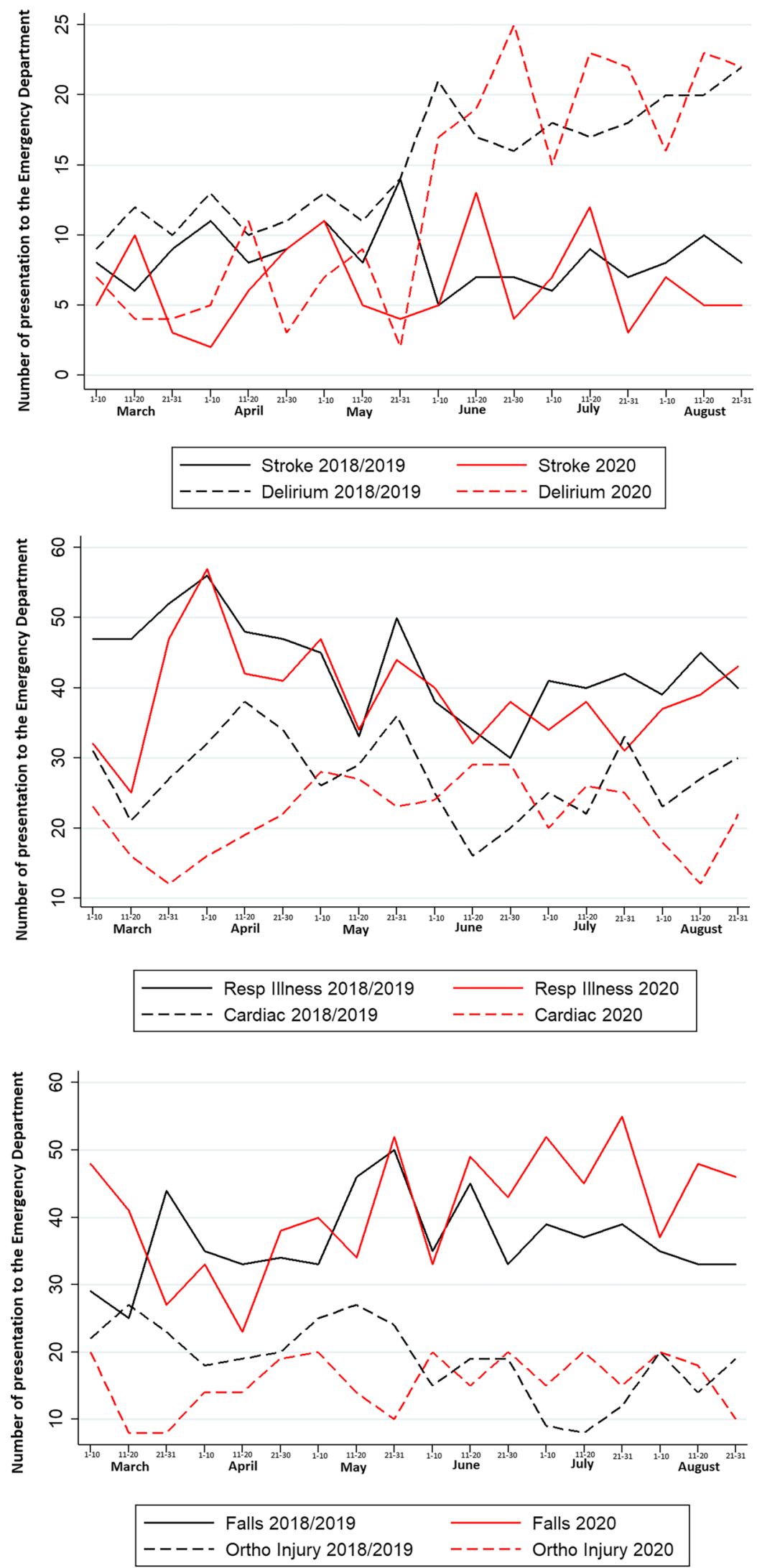
Table 3 Logistic regression model with admission to hospital as dependent variable

\begin{tabular}{llll}
\hline & Odds ratio (95\% CI) & $Z$ & $p$ \\
\hline Age range: (Ref: 70-79 years) & $1.34(1.24-1.46)$ & 7.08 & $<0.001$ \\
Age 80-89 years & $1.69(1.45-1.96)$ & 6.78 & $<0.001$ \\
Age $\geq 90$ years & & & \\
Male sex & $1.09(1.01-1.17)$ & 2.10 & 0.036 \\
Manchester Triage Score: (Ref: 3) & $3.54(2.57-4.88)$ & 7.74 & $<0.001$ \\
MTS 1 & $4.21(3.85-4.61)$ & 31.18 & $<0.001$ \\
MTS 2 & $0.21(0.18-0.25)$ & -19.58 & $<0.001$ \\
MTS 4 & $0.14(0.07-0.31)$ & -4.89 & $<0.001$ \\
MTS 5 & & & \\
Presenting complaint; (Ref: other PC) & $2.56(2.28-2.89)$ & 15.59 & $<0.001$ \\
Respiratory & $1.00(0.87-1.15)$ & 0.04 & 0.969 \\
Cardiac & $1.10(0.87-1.15)$ & 1.72 & 0.086 \\
Falls & $4.72(3.36-6.62)$ & 8.97 & $<0.001$ \\
Stroke & $5.75(4.28-7.73)$ & 11.57 & $<0.001$ \\
Delirium & $0.80(0.68-0.94)$ & -2.69 & 0.007 \\
Ortho injury & & & $<0.001$ \\
Presenting during COVID-19 Wave 1 (Ref: pre- & $1.18(1.09-1.28)$ & 3.87 & \\
$\quad$ senting at same period in 2018/2019) & & & \\
\hline
\end{tabular}

Logistic regression model reporting odds ratios with $95 \%$ confidence intervals; dependent variable =admission to hospital

ref reference value, MTS Manchester Triage Score, $P C$ presenting complaint, Ortho orthopaedic

\section{Discussion}

This study examines ED presentations of older people during the early stages of the first wave of the COVID-19 pandemic, compared to the same period in 2018 and 2019. Overall, during these first 6 months of the pandemic there was a $16 \%$ reduction in the number of presentations to the ED with much of this due to lower numbers in March, April and early May 2020, when older people were advised to cocoon at home. Numbers began to climb back towards preCOVID-19 levels in late May when restrictions were eased but decreased again in August 2020 after further easing of restrictions was deferred. There was no observable 'spike' in presentations during periods of eased restrictions within these first 6 months of the pandemic.

Overall, this equates to 4 fewer people aged $\geq 70$ years presenting to the ED per day during the initial 6 months of the COVID-19 pandemic and goes against established trends of increasing numbers of frail older people presenting to acute unscheduled care in recent years. Prior studies have demonstrated significant decline in ED attendances during the COVID-19 pandemic [9, 10], including in an Irish context [13], but to our knowledge, this is the first study to examine the impact of the pandemic on the pattern and nature of ED attendance in older people.

Older people have been disproportionately affected by the COVID-19 pandemic, potentially leading to higher levels of COVID-19-related worry and concern [15]. A significant proportion of older people have deferred seeking medical attention for non-COVID-19 illnesses during the pandemic, often for fear of contracting COVID-19 $[14,16]$.
Different trends were seen depending on presenting complaint. While presentations with respiratory illness declined by over $40 \%$ in March 2020 compared to prior years, they were relatively similar thereafter. We have previously demonstrated, within this same cohort of frail older adults, that over $40 \%$ reported a decline in their physical health while cocooning, and almost $70 \%$ reported exercising less frequently or not exercising at all [14]. It is not surprising then that in the three months following the easing of cocooning restrictions, there was a $25 \%$ increase in falls and orthopaedic injuries compared to previous years. The significant rise in presentations of delirium, which increased by over onequarter in this same time frame, is less expected but may be related to increased recognition of symptoms from carers or family members from whom the patient had been socially distanced up to then.

Overall, presentations with stroke and cardiac problems were one-fifth lower over the 6-month period compared to the average of 2018 and 2019, with relatively fewer numbers in each month except June, where there was an increase in both cardiac and stroke-related presentations (by $37 \%$ and $15 \%$, respectively) as the country had a lower 7 -day average number of new COVID-19 cases of 7-50 [17]. Similar trends have been seen elsewhere, with a large Stroke Centre in the US reporting a $38 \%$ fall in new stroke diagnoses during the initial 6 weeks of the COVID-19 pandemic but no change in the numbers presenting with large vessel occlusions, raising the possibility of fewer patients presenting with minor stroke symptoms [18]. A seasonal variation in terms of stroke incidence and mortality has been proposed previously and it is 
also possible that COVID-19-related restrictions may have reduced stroke incidence [19].

Similarly, tertiary centres have reported a decline in the number of patients presenting with myocardial infarction during the pandemic, particularly those with no-ST segment elevation myocardial infarction [20], with studies demonstrating longer times from symptom onset to presentation [21] and of patients declining hospital admission [22]. Given that further pandemic-related lockdowns are a possibility going forward, it is imperative that we deliver the message to older people that deferring medical assessment and care when unwell is unsafe and generally not in their best interests, particularly in the case of complaints such as chest pain or acute neurological symptoms.

The mean MTS for patient visits was higher in 2020 than $2018 / 19$, suggesting lower acuity illness. There was an $18 \%$ higher likelihood of admission when presenting during the pandemic however, after adjusting for covariates including MTS. The differences between 2020 and prior years are relatively marginal, however, with similar rates of 'Category 2' patient visits. An older person presenting during the first wave of a global pandemic may have been viewed differently to those presenting at other times, which may explain the discrepancy in admission rates. It must also be noted that the MTS may not be an ideal tool to quantify illness severity in frail, older people [23].

There are some limitations to this study which should be noted. Data collection was retrospective and involved a single centre only. Categorisation of presenting complaint was based on the HIPE code selected at triage assessment by nursing staff for the patient visits and not on further objective measures/assessment, as it was not be feasible to incorporate further assessment information on the 14,000 patient visits included in the study. Categorisation of "delirium' was based on the HIPE code selected at triage also and could therefore also include patients presenting with behavioural symptoms in the context of dementia, encephalitis, or encephalopathy. The strengths of the study include the large sample of almost 14,000 ED presentations and the fact that this is the first study to examine the impact of the first wave of the COVID-19 pandemic on ED visits by older people.

In conclusion, this study demonstrates a significant decline in the numbers of older people presenting to the ED for acute unscheduled care, including for potentially time-dependent illnesses such as stroke or cardiac problems. During periods of 'lockdown', presentations with falls and orthopaedic injuries declined but increased significantly beyond previous norms once restrictions were eased. Presenting to the ED remains the most frequent route by which unwell older people access acute hospital care and it is vitally important that they continue to do so in a timely manner when necessary. Given the possibility of further lockdowns and restrictions, this message needs to be communicated to older people clearly by healthcare professionals and governmental bodies to mitigate against adverse outcomes related to delayed or deferred care.

Funding Open Access funding provided by the IReL Consortium.

Availability of data/material Not applicable.

Code availability Not applicable.

\section{Declarations}

\section{Conflict of interest None.}

Ethical approval For this service analysis was obtained from the St James's Hospital Research \& Innovation Office (Project No 6300).

Informed consent As this was a service analysis informed consent of participants was not obtained.

Open Access This article is licensed under a Creative Commons Attribution 4.0 International License, which permits use, sharing, adaptation, distribution and reproduction in any medium or format, as long as you give appropriate credit to the original author(s) and the source, provide a link to the Creative Commons licence, and indicate if changes were made. The images or other third party material in this article are included in the article's Creative Commons licence, unless indicated otherwise in a credit line to the material. If material is not included in the article's Creative Commons licence and your intended use is not permitted by statutory regulation or exceeds the permitted use, you will need to obtain permission directly from the copyright holder. To view a copy of this licence, visit http://creativecommons.org/licenses/by/4.0/.

\section{References}

1. McCabe JJ, Kennelly SP (2015) Acute care of older patients in the emergency department: strategies to improve patient outcomes. Open Access Emerg Med 7:45-54

2. Chenore T, Pereira Gray DJ, Forrer J, Wright C, Evans PH (2013) Emergency hospital admissions for the elderly: insights from the Devon Predictive Model. J Public Health (Oxf) 35(4):616-623

3. Pines JM, Mullins PM, Cooper JK, Feng LB, Roth KE (2013) National trends in emergency department use, care patterns, and quality of care of older adults in the United States. J Am Geriatr Soc 61(1):12-17

4. Burkett E, Martin-Khan MG, Scott J, Samanta M, Gray LC (2017) Trends and predicted trends in presentations of older people to Australian emergency departments: effects of demand growth, population aging and climate change. Aust Health Rev 41(3):246-253

5. Miles A, Webb TE, Mcloughlin BC, Mannan I, Rather A, Knopp P, Davis D (2020) Outcomes from COVID-19 across the range of frailty: excess mortality in fitter older people. Eur Geriatr Med 11(5):851-855

6. Lithander FE, Neumann S, Tenison E, Lloyd K, Welsh TJ, Rodrigues JCL, Higgins JPT, Scourfield L, Christensen H, Haunton VJ, Henderson EJ (2020) COVID-19 in older people: a rapid clinical review. Age Ageing 49(4):501-515 
7. Kennelly B, O'Callaghan M, Coughlan D, Cullinan J, Doherty E, Glynn L, Moloney E, Queally M (2020) The COVID-19 pandemic in Ireland: an overview of the health service and economic policy response. Health Policy Technol 9(4):419-429

8. Armitage R, Nellums LB (2020) COVID-19 and the consequences of isolating the elderly. Lancet Public Health 5(5):e256

9. Hughes HE, Hughes TC, Morbey R, Challen K, Oliver I, Smith GE, Elliot AJ (2020) Emergency department use during COVID19 as described by syndromic surveillance. Emerg Med J 37(10):600-604

10. Hartnett KP, Kite-Powell A, DeVies J, Coletta MA, Boehmer TK, Adjemian J (2020) Gundlapalli AV (2020) National Syndromic Surveillance Program Community of Practice. Impact of the COVID-19 Pandemic on Emergency Department Visits - United States, January 1, 2019-May 30. MMWR Morb Mortal Wkly Rep 69(23):699-704

11. Solis E, Hameed A, Brown K, Pleass H, Johnston E (2020) Delayed emergency surgical presentation: impact of corona virus disease (COVID-19) on non-COVID patients. ANZ J Surg 90(7-8):1482-1483

12. Pikoulis E, Solomos Z, Riza E, Puthoopparambil SJ, Pikoulis A, Karamagioli E, Puchner KP (2020) Gathering evidence on the decreased emergency room visits during the coronavirus disease 19 pandemic. Public Health 185:42-43

13. Brick A, Walsh B, Keegan C, Lyons S. COVID-19 and emergency department attendances in Irish public hospitals. Report from The Economic and Social Research Institute. Available at: https://www.esri.ie/publications/covid-19-and-emergency-depar tment-attendances-in-irish-public-hospitals

14. Bailey L, Ward M, DiCosimo A, Baunta S, Cunningham C, Romero-Ortuno R, Kenny RA, Purcell R, Lannon R, McCarroll K, Nee R, Robinson D, Lavan A, Briggs R (2021) Physical and Mental Health of Older People while Cocooning during the COVID-19 Pandemic. QJM. 2021:hcab15

15. Bergman YS, Cohen-Fridel S, Shrira A, Bodner E, Palgi Y (2020) COVID-19 health worries and anxiety symptoms among older adults: the moderating role of ageism. Int Psychogeriatr 32(11):1371-1375
16. Ward M, O' Mahony P, Kenny RA. Altered Lives in a Time of Crisis: The Impact of the COVID-19 Pandemic on the Lives of Older People in Ireland. Report from The Irish Longitudinal Study on Ageing. Available at: https://tilda.tcd.ie/publications/reports/ C19ReportKeyFindings/index.php

17. Epidemiology of COVID-19 in Ireland - daily reports, June 2020. https://www.hpsc.ie/a-z/respiratory/coronavirus/novelcoronavirus/ casesinireland/epidemiologyofcovid-19inireland/june2020/

18. Siegler JE, Heslin ME, Thau L, Smith A, Jovin TG (2020) Falling stroke rates during COVID-19 pandemic at a comprehensive stroke center. J Stroke Cerebrovasc Dis 29(8): 104953

19. Lanska DJ, Hoffmann RG (1999) Seasonal variation in stroke mortality rates. Neurology 52(5):984-990

20. Metzler B, Siostrzonek P, Binder RK, Bauer A, Reinstadler SJ (2020) Decline of acute coronary syndrome admissions in Austria since the outbreak of COVID-19: the pandemic response causes cardiac collateral damage. Eur Heart J 41(19):1852-1853

21. Arai R, Fukamachi D, Ebuchi Y, Migita S, Morikawa T, Monden M, Takei N, Tamaki T, Kojima K, Akutsu N, Murata N, Kitano D, Okumura Y (2021) Impact of the COVID-19 outbreak on hospitalizations and outcomes in patients with acute myocardial infarction in a Japanese Single Center. Heart Vessels. 2021:1-10

22. Ma T, Huang Y, Li W, Zhong J, Yang H, Zhou Y, Li M, Zhong W, Cao Y, Lu S, Hu Y (2021) The number of patients with acute myocardial infarction decreased and door-to-balloon time delayed in COVID-19. Cardiol Res Pract 2021:6673313

23. Brouns SHA, Mignot-Evers L, Derkx F, Lambooij SL, Dieleman JP, Haak HR (2019) Performance of the Manchester triage system in older emergency department patients: a retrospective cohort study. BMC Emerg Med 19(1):3

Publisher's Note Springer Nature remains neutral with regard to jurisdictional claims in published maps and institutional affiliations. 